\title{
Physicians and regionalization in Canada: past, present and future
}

— Cite as: CMAJ 2017 September 11;189:E1147-9. doi: 10.1503/cmaj.170164

T he way in which health care is structured and managed in Canada is undergoing upheaval. There is a crisis of confidence in regionalization, arguably the most important reform since medicare - the administrative structures chosen by provincial and territorial governments to integrate and coordinate institutional and community-based health services to improve the health of populations within defined geographic regions.

Saskatchewan is the latest jurisdiction, after the Northwest Territories this year, Nova Scotia in 2016, and Alberta in 2008, to eliminate its regional health authorities in favour of one centralized administrative authority. Manitoba and New Brunswick have reduced the number of health regions. At the same time, Ontario is going in the opposite direction by creating miniregions within each of its 14 Local Health Integration Networks (LHINs).

These approaches seem contradictory, and they have upset many providers and their patients. Physicians in particular have had a conflicted relationship with regionalization: at times strongly opposed to regional structures and management and at others disdainful of "regional bureaucracies," with some arguing that they are a superfluous and expensive layer that adds little or no value to the real business of delivering health care services. However, for regionalization to be repaired or rebuilt into an effective system with the support of the public and their governments, physicians will have to be part of the solution.

The origins of the concept of regionalization in Canada can be traced to the United Kingdom and the Consultative Council on Medical and Allied Services (chaired by Sir Bertrand Dawson, later Lord Dawson) as part of reconstruction after the First World War. In his 1920
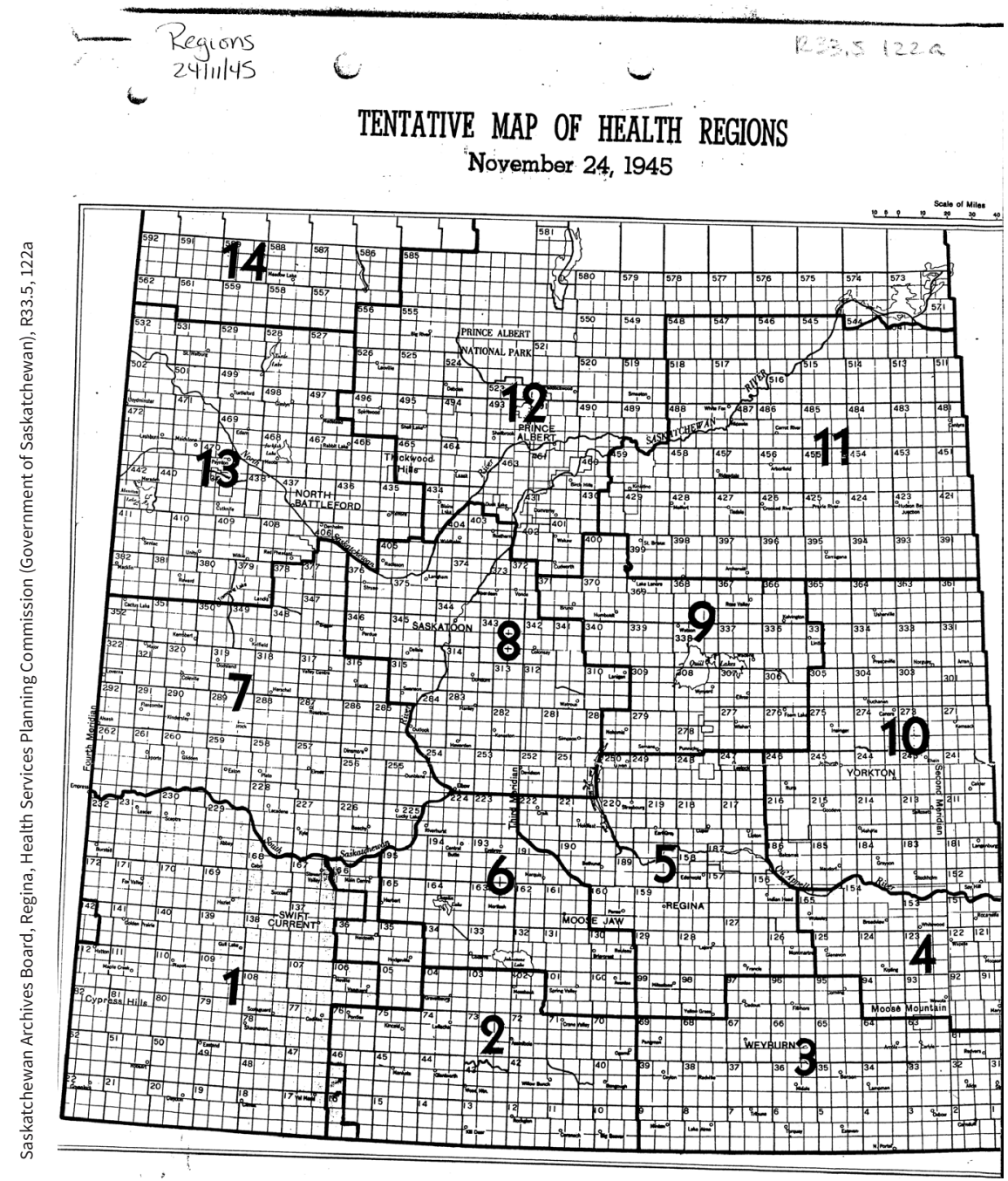

Saskatchewan health regions as first proposed in 1945.

report, Dawson envisaged an integrated health system that coordinated illness prevention and health promotion with primary, secondary, tertiary and long-term care. Public health authorities would manage primary health centres linked to secondary and tertiary care hospitals on behalf of geographically defined populations within the UK. ${ }^{1}$
Although the Dawson report was largely dismissed as utopian, the ideas would be resurrected with the establishment of the National Health Service (NHS) following the Second World War and the subsequent regionalization of the NHS in 1974. ${ }^{2}$ No doubt this pleased Lord Dawson, a physician of great standing and widely known as the Royal Family's physician - a 
luster somewhat diminished after his death when it was revealed that, without consultation with the two other attending doctors or the family, he hastened the death of King George VI in 1936 with a lethal injection of cocaine and morphine. ${ }^{3}$

The idea of regionalization eventually reached Canada when a newly elected Tommy Douglas reconstructed the health system in Saskatchewan. As both premier and minister of public health, Douglas invited Dr. Henry Sigerist of Johns Hopkins University, who was a world-famous medical historian and advocate of socialized medicine, to conduct a study of the health system. Sigerist recommended that Sas-
Current experiment. This opposition continued through the next decades and blocked successive governments from implementing a regionalized system of health delivery until the early 1990s when a fiscal crisis forced a change.

In 1992, the newly elected New Democratic Party government under Roy Romanow introduced 33 health districts. The reform devolved the lion's share of the health budget to the new organizations, shut down or converted highly inefficient and ineffective rural hospitals, and centralized governance and management of previously independent hospitals and health care organizations into the health authority boards.

\section{"... no provincial government is prepared to go back to a time when they were simply the passive payers of hospital and medical bills ..."}

katchewan be divided into health regions that would provide public health as well as tax-funded prepaid treatment services based on local government structures. ${ }^{4}$ Although it was launched in 1945, this regionalized system was stillborn because most regions limited their mandates to public health and only one region - Swift Current - offered tax-funded (prepaid) health coverage for hospital and medical care services. $^{5}$

Most physicians in Saskatchewan were opposed to Sigerist's idea from the beginning. They thought regionalization would only encourage more hiring of physicians on salary by local governments, which would convert independent clinicians into dependent and pliable employees. The medical establishment breathed a sigh of relief when the experiment in Swift Current was disbanded in the 1960s after universal medicare was introduced. The irony is that almost all of the province's physicians had opposed the centralized system of universal coverage for medical care that ultimately caused the demise of the Swift
Although more severe in Saskatchewan, public debt and deficits had grown to unsustainable levels for almost all other provincial governments in Canada, and they also introduced regionalization in an effort to gain better value for money while improving services across diverse health sectors. By 1995, every province in Canada, except Ontario, had implemented a regionalized structure. In 2005, Ontario tentatively joined the bandwagon by creating LHINs, organizations that were expected to monitor and coordinate services without owning and directly managing these same services - a change mockingly called "regionalization light" by some policy experts.

Most physicians, at least those represented by their provincial medical associations, were highly sceptical of the benefits of regionalization. They fought against any proposal that would have seen physician remuneration flow from provincial departments or ministries of health to regional health authorities (RHAs) or LHINs. They held to the originating medicare bargain in which physicians would preserve their separateness from a government-directed health system as independent contractors shielded by fee-for-service remuneration. ${ }^{6}$ Eager to avoid confrontations with organized medicine while struggling with other stakeholders including hospital boards and associations, provincial governments unanimously shelved any notion of making RHAs the paymasters for physicians and, therefore, truly responsible for integrating physician services into the regions.

The consequence of this decision would be momentous. Regional health authorities would have no governance relationship with physicians, and physicians would have no accountability back to the health care organizations and systems they worked in. Because most primary care is delivered by physicians whose contracts are with the provincial government, not the RHAs, this put the provision of primary care outside the authority of RHAs. In other countries with regionalized structures, such as Denmark ${ }^{7}$ and New Zealand, ${ }^{8}$ primary care physicians contract with RHAs and not the central government. For specialists, it meant that they have little stake in RHAs despite the fact that RHAs own and manage (or contract with) the hospitals or other facilities and equipment that specialists required to diagnose and treat patients. This missing link would impede system coordination and frustrate physicians in providing more seamless and timely care for patients.

Based on the assessment of international performance in primary care and continuity of care by the Commonwealth Fund - so much of which depends on a primary care physician's ability to coordinate care through the rest of the system on their patient's behalf - Canada fares poorly. Although it is difficult to isolate the precise reasons for this embarrassing performance, surely this illogical arrangement contributes to the problem.

Given the truncated nature of regionalization in Canada, it is hardly surprising that this quarter-century experiment is viewed by many physicians and their patients as a failure. This viewpoint is also gaining momentum among politicians. Hardly a provincial election goes by without a political party calling for the reduction or the abolition of RHAs in an effort to reduce "unnecessary" bureaucracy. ${ }^{9}$ At the 
same time, no provincial government is prepared to go back to a time when they were simply the passive payers of hospital and medical bills, with only the crudest levers available to control health spending and absolutely no ability to prevent the fragmentation of service delivery.

In fact, all provincial governments are keeping or enhancing administrative controls over their respective health systems. Some achieve this through greater centralization using single provincial health authorities that are only one small step from health ministers and their strategic and policy advisors in the health ministries. Ontario has taken a different approach through the Patients First Act, 2016, and by establishing a new administrative layer of sub-LHINs, in which the ministry retains broad ability to pull back its delegation when it sees fit. ${ }^{10}$

So where do we go from here? Physicians need to play a larger role in the reshaping of regionalization because governments are not likely to return (nor should they) to a pre-1990s passive payment approach. This means rethinking the profession's original opposition to regionalization and working with provincial governments on more innovative and accountable organizational structures that will, operationally, put primary care and the health of the population at the centre of the health care system as proposed in the Dawson report almost a century ago. At the same time, provincial governments need to recognize the flaw that lies at the heart of the design of Canadian regionalization and get on with building a structure capable of delivering high-quality, timely and coordinated health services to their residents. This cannot be done without physicians being an accountable and integrated part of the organizations administering our health delivery systems in Canada. The benefit is that physicians will have greater ability to ensure that patients get quality care in a system that is timely and responsive.

\section{Gregory P. Marchildon PhD}

Institute of Health Policy, Management and Evaluation, University of Toronto, Toronto, Ont.

\section{References}

1. Consultative Council on Medical and Allied Services. Interim report on the future provision of medical and allied services. London: Ministry of Health; 1920.

2. Webster $\mathrm{C}$. The health services since the war, volume 1: problems of health care - the National Health Service before 1957. London: Her Majesty's Stationary Office; 1988:19.

3. Ramsay JHR. A king, a doctor, and a convenient death. BMJ 1994;308:1445.

4. Sigerist HE. Saskatchewan Health Services Survey Commission: report of the Commissioner presented to the Minister of Public Health, October 4th. Regina (SK): King's Printer; 1944.

5. Marchildon GP. Regionalization and health services restructuring in Saskatchewan. In Beach M, editor. Health services restructuring in Canada: new evidence and new directions. Kingston (ON): McGill-Queen's University Press: 2006;33-57.

6. Naylor CD. Private practice, public payment: Canadian medicine and the politics of health insurance, 1911-1966. Montréal: McGill-Queen's University Press; 1986.

7. Vrangbæk K. Regionalization lessons from Denmark. Healthc Pap 2016;16:21-6.

8. Tenbensel T. Health system regionalization - the New Zealand experience. Healthc Pap 2016;16: 27-33.

9. Marchildon GP. The crisis of regionalization. Healthc Manage Forum 2015;28:236-8.

10. Marchildon GP. Regionalization: What have we learned? Healthc Pap 2016;16:8-14.

This article has been peer reviewed. 